\title{
Asthma in Competitive Cross-Country Skiers: A Systematic Review and Meta-analysis
}

\author{
${\text { Rikhard Mäki-Heikkilä }{ }^{1} \text { (D) Jussi Karjalainen }}^{1,2}$ D $\cdot$ Jari Parkkari $^{3}$ D $\cdot$ Maarit Valtonen $^{4}$ (D) Lauri Lehtimäki $^{1,2} \mathbb{D}$
}

Published online: 11 September 2020

(c) The Author(s) 2020

\begin{abstract}
Introduction In cross-country skiing, the repetitive ventilation of large amounts of cold and dry air strains the airways. The aim of this systematic review was to establish an overview of the current literature on asthma in cross-country skiers, biathletes and ski-orienteers.

Methods Six databases were searched on August 29, 2019. The search yielded 2161 articles. Thirty articles fulfilled the search criteria and were pooled together for a qualitative synthesis. Eight articles were included in the meta-analysis on the prevalence of asthma and the use of asthma medication.

Results According to the meta-analysis, the prevalence of self-reported physician-diagnosed asthma in skiers was $21 \%$ (95\% CI 14-28\%). The onset age of asthma was higher in skiers than in non-skiers with asthma. The prevalence of asthma medication use was on average 23\% (CI 95\% 19-26\%). Several studies reported that asthma was underdiagnosed in skiers, as previously healthy skiers without a prior asthma diagnosis or medication use were frequently found to fulfill diagnostic criteria for asthma according to lung function tests. Studies using bronchial biopsy demonstrated that eosinophilic asthma is not detected in skiers with asthma as often as it is in non-skiers with asthma and that there are signs of airway inflammation even in non-asthmatic skiers.

Conclusion Our findings suggest that the accuracy and coverage of diagnosing asthma in skiers has improved over the recent decades. However, the optimal treatment and natural course of asthma in this population remain unclear. Future research should investigate how the intensity of training, airway infections and their treatment affect the development of asthma among skiers.
\end{abstract}

PRD registration number CRD42017070940.

\section{Abbreviations}

EIB Exercise-induced bronchoconstriction

EVH Eucapnic voluntary hyperpnoea

Electronic supplementary material The online version of this article (https://doi.org/10.1007/s40279-020-01334-4) contains supplementary material, which is available to authorized users.

Lauri Lehtimäki

lauri.lehtimaki@tuni.fi

1 Faculty of Medicine and Health Technology, Tampere University, Tampere, Finland

2 Allergy Centre, Tampere University Hospital, Tampere, Finland

3 Tampere Research Center of Sports Medicine, UKK Institute, Tampere, Finland

4 KIHU, Research Institute for Olympic Sports, Jyväskylä, Finland

\begin{abstract}
AMP Adenosine 5'-monophosphate
MMEF Maximal mid-expiratory flow
\end{abstract}

\section{Introduction}

Asthma is a heterogeneous disease characterized by variable airway obstruction and is usually associated with chronic airway inflammation. It is defined by a history of respiratory symptoms, such as wheezing, shortness of breath, chest tightness and coughing that varies over time and in intensity, together with variable expiratory airflow limitations [1]. Airway inflammation, airway hyperresponsiveness and bronchoconstriction during or after exercise are common pathophysiological features related to asthma. The diagnosis of asthma is recommended to be based on typical symptoms and objective evidence of variable airway obstruction [1]. The most frequently used methods of diagnosis are spirometry with the bronchodilation test or tests of bronchial 


\section{Key Points}

The prevalence of asthma in cross-country skiers is 21 $\%$, which is higher than that in the general population.

There is an indication that asthma is underdiagnosed among skiers, especially during the previous decades, as many skiers without previous diagnosis of asthma or asthma medication fulfilled criteria for asthma according to lung function tests.

There is a need for international consensus over the criteria of asthma and its treatment in athletes to avoid both over and under diagnosis of asthma.

The usual onset age of asthma in cross-country skiers is 10-17 years of age, which is different from that in the general population, for whom the onset more often occurs in early childhood.

The prevalence of asthma and use of asthma medication ( $21 \%$ vs. $23 \%$ ) were similar, suggesting that there is no remarkable overuse of asthma medication among skiers. However, the data is limited on the use of asthma medication in skiers without diagnosis of asthma.

Asthma in skiers seems to be less often eosinophilic and more often neutrophilic compared to asthma in nonskiers.

Due to the high prevalence of asthma in cross-country skiers, regular screening of asthma-like symptoms and lung function could be beneficial to competitive skiers.

hyperresponsiveness (e.g., exercise tests or methacholine challenge tests) $[2,3]$.

The prevalence of physician-diagnosed asthma is reported to be $4.3 \%$ globally [4] and approximately $8-12 \%$ in countries, where cross-country skiing is popular, such as Nordic countries, France, and North America [4-7]. The prevalence of asthma among athletes varies notably between sports. Athletes who engage in sports with high ventilatory requirements, such as endurance sports, have a higher prevalence of asthma than athletes who engage in low ventilatory sports, such as archery or shooting [8]. Additionally, the use of asthma medications, such as $\beta_{2}$-agonists, varies between sports. In the Winter Olympic Games from 2002 until 2010, the approved usage rate for $\beta 2$-agonists was the highest in cross-country skiing and Nordic combined (17.2\% and $12.9 \%$, respectively), while the usage rate was the lowest in ski jumping and the luge (3.1\% and $2.7 \%$, respectively) [9].

Cross-country skiing is a demanding Olympic winter sport. High maximal oxygen uptake and anaerobic capacity are needed in addition to high levels of upper body power
[10]. Minute ventilation in elite skiers may well exceed 200 1/min, and their forced vital capacity (FVC) and forced expiratory volume in one second (FEV1) often exceed normal values [11]. Skiers may train in very dry and cold air that reaches extremely low temperatures. The International Ski Federation (FIS) set a temperature limit for organizing competitions, and it is currently $-20{ }^{\circ} \mathrm{C}\left(-4{ }^{\circ} \mathrm{F}\right)$ [12]. The absolute humidity of cold air is very low, which may exacerbate symptoms and promote bronchial constriction in people with pre-existing asthma [13]. Repeated exposure to cold air over many years of intensive training may also cause airway inflammation and asthma [14, 15].

To the best of our knowledge, no systematic reviews on asthma in cross-country skiers have been published. Our aim was to establish a systematic review of the literature on all available aspects of asthma in cross-country skiers.

\section{Methods}

This systematic review followed the Preferred Reporting Items for Systematic Reviews and Meta-Analysis (PRISMA) guidelines [16] and was registered in the PROSPERO database (registration number CRD42017070940).

\subsection{Literature search}

Original articles from PubMed, EBSCO Academic Search Premier, Web of Science, Scopus, Cochrane Library and clinicaltrials.gov were searched. The search date was August 29, 2019. No language or time filters were used. The details of the search strategy are presented in Supplementary File 1. After study selection, the references from these articles were screened for further references.

\subsection{Study inclusion}

Three authors (RM-H, JK, LL) independently screened the titles and abstracts of the studies. The studies had to meet the following criteria to be included: (1) The study participants were active, competitive cross-country skiers, biathletes, Nordic combined athletes or ski-orienteers, i.e., athletes who compete using cross-country skis. (2) The study produced new original data on the prevalence, incidence or pathophysiology of asthma, physiological phenomena related to asthma or asthma-related symptoms or asthma medication.

The exclusion criteria for our review were as follows: (1) the study population included skiers, but their results were not reported separately from those of other athletes, and (2) the subjects were recreational skiers not competitive skiers. 


\subsection{Data extraction}

From each included study, we extracted the first author, country of the study, publication year, title, study population and characteristics, test protocols, prevalence of selfreported or physician-diagnosed asthma, asthma-related symptoms and environmental factors, allergies and other respiratory diseases, study funding and conflicts of interest. One reviewer (RM-H) extracted the data, and two other authors (JK and LL) verified the correctness of the collected data.

\subsection{Quality appraisal and data analyses}

Three authors (RM-H, JK, LL) reviewed the risk of bias in the included studies in collaboration using the Cochrane risk of bias tool. Meta-analyses were conducted by calculating Freeman-Tukey-transformed [62] proportions and summary estimates with a random effects model using a restricted maximum likelihood (REML)-approach (transformed prevalence of self-reported physician-diagnosed asthma, asthma in skiers with either a self-reported physician diagnosis or a diagnosis based on lung function measurements, and the use of asthma medication). Inverse variance weighting was used to calculate the weights for individual studies. After performing the meta-analyses, individual proportions and summary estimates were back-transformed according to Miller [63]. Forest plots were then drawn using the backtransformed data. The analyses were conducted using $\mathrm{R}$ version 3.4.3 [17] and R-package Metafor [18]. Other outcomes are presented narratively.

\section{Results}

The initial search yielded 2257 articles. After the duplicates were removed, the titles and abstracts of the remaining 2161 articles were screened. Based on the screening results, the full texts of 163 articles were retrieved for analysis. On the basis of the full-text analysis, 130 articles were excluded, while 33 articles fulfilled the inclusion criteria. See Supplemental file 3 for reasons. After the risk of bias assessment, 2 articles were excluded due to a very high risk of bias $[65,66]$ and after careful consideration these studies were excluded from the analyses. Data from 31 articles were extracted for the qualitative synthesis. Eight articles were included in the meta-analysis to assess the prevalence of asthma and the use of asthma medication (Fig. 1) [19-24, 26, 27] After study inclusion, the references from selected articles were screened but no additional records were found.

The publication years of the included studies ranged from 1993 to 2018. Ten articles were epidemiological studies and assessed the prevalence of asthma, onset of asthma, prevalence of asthma-related symptoms and use of asthma medication [19-27, 46]. Fourteen studies assessed different diagnostic tests for asthma [14, 15, 28-39]. Three studies investigated seasonal variability of asthmatic features [40-42], and two studies investigated the effects of bronchodilating asthma medication in healthy skiers $[43,44]$. One study investigated the predictive values of asthma-related symptoms [56] and one case study followed four skiers during a 10-year period [45]. The risk of bias assessment results are shown in electronic Supplementary File 2.

\subsection{Prevalence of asthma-related symptoms}

Asthma-related symptoms include chest tightness, shortness of breath, coughing and wheezing. The prevalence of these symptoms has been studied in different studies using structured questionnaires. In a study by Heir and Oseid [21], 84\% of 153 skiers had at least one symptom. Sue-Chu et al. [22] found that $46 \%$ of the skiers studied in Norway and $51 \%$ of those studied in Sweden had wheezing and breathlessness or chest tightness. In a screening study by Turmel and others, $50 \%$ of 44 skiers and biathletes had exercise-induced symptoms [25]. Norqvist et al. [26] found that $22 \%$ of the skiers $(n=238)$ had asthma-related symptoms. In the study by Rundell and others [46], $62 \%$ of the population of crosscountry skiers $(n=21)$ reported at least one symptom.

There was a significant difference in the prevalence of asthma symptoms between sexes among 15-19-year-old skiers ( $10 \%$ in males vs. $30 \%$ in females, $p=0.001)$ but not in the 20-34-year-old group (24\% in males vs. $29 \%$ in females, $p=0.582$ ) [26]. In a study by Eklund and colleagues [27], $16 \%$ of high-school aged skiers had asthma-related symptoms. They also found a significant difference in the prevalence of symptoms between sexes (9\% in males vs. $23 \%$ in females, $p=0.005$ ) [27].

\subsection{Prevalence of asthma}

Studies investigating the prevalence of asthma were divided into three categories based on how asthma was defined and diagnosed: (1) self-reported physician-diagnosed asthma; (2) asthma diagnosed based on lung function measures as part of the study; (3) either self-reported physician-diagnosed asthma or asthma diagnosed based on lung function tests in the study.

\subsubsection{Studies reporting prevalence of self-reported physician-diagnosed asthma}

Postal self-administered questionnaires were used in five studies to assess the prevalence of self-reported physiciandiagnosed asthma (Fig. 2, Table 1). The mean prevalence 


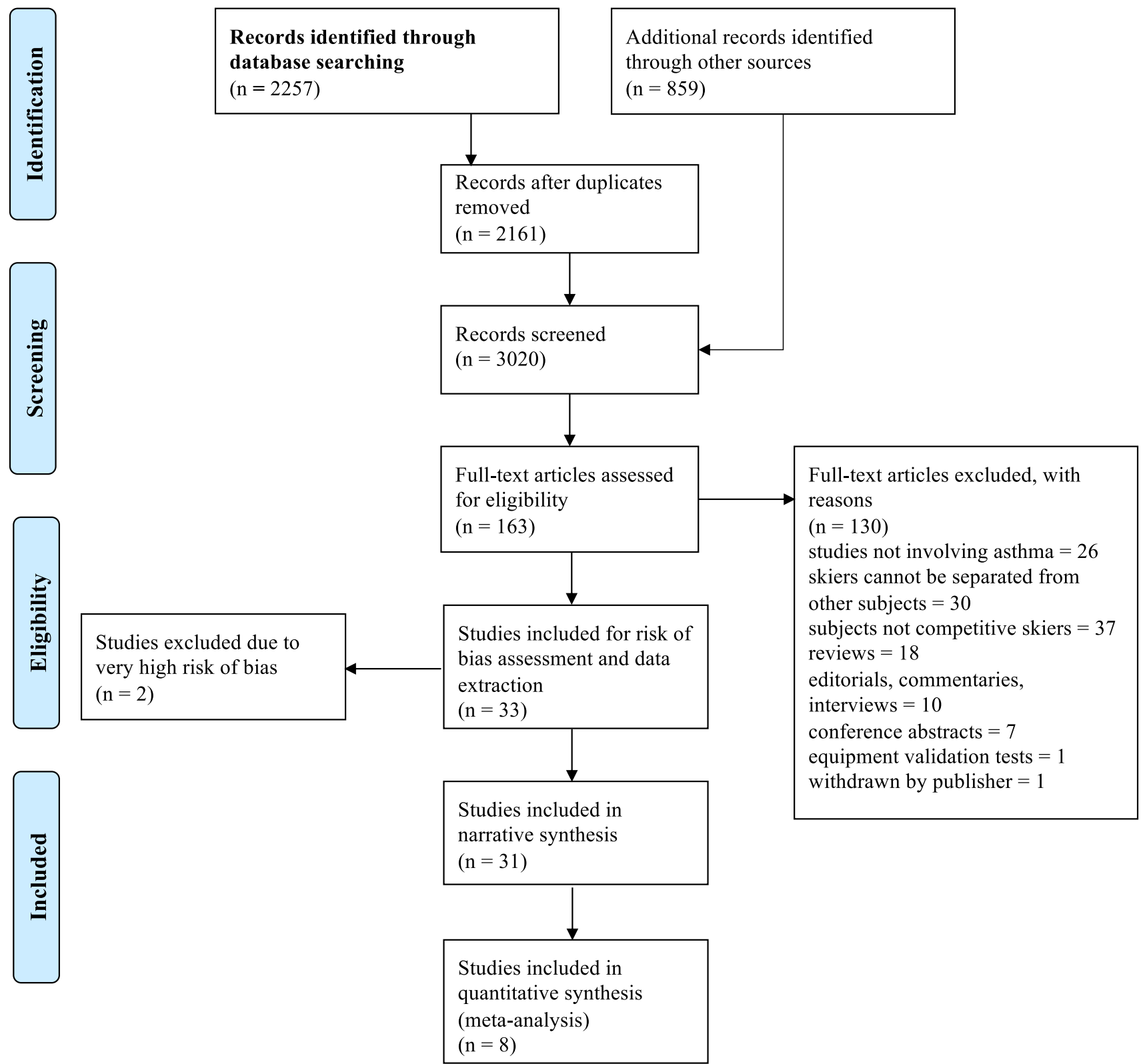

Fig. 1 Flowchart of the search performed according to the PRISMA guidelines

of asthma in these five studies was 21\% (CI 95\% 14-28\%). Based on these studies, the prevalence of self-reported asthma seems to have increased over time.

Subgroup analysis results for the prevalence of selfreported physician-diagnosed asthma in different age groups and sexes were reported by Norqvist et al. [26]. In skiers between 15 and 19 years of age, the overall prevalence of asthma was $29 \%$, and it was significantly higher in females $(38 \%)$ than in males $(21 \%, p=0.016)$. In skiers from 20 to 34 years of age, the prevalence of asthma was $35 \%$, and there was no difference between sexes (32\% in males vs. $39 \%$ in females, $p=0.492$ ).

\subsubsection{Studies reporting prevalence of asthma based on current lung function measures}

We found only one study, where the criteria for asthma were having asthma-like symptoms and current lung function tests as part of the study protocol showed results compatible with asthma. Turmel et al. [25] screened athletes in Quebec, 
Fig. 2 Forest plot of the studies reporting the prevalence of selfreported physician-diagnosed asthma in 957 subjects

\section{Self-reported physician-diagnosed asthma}

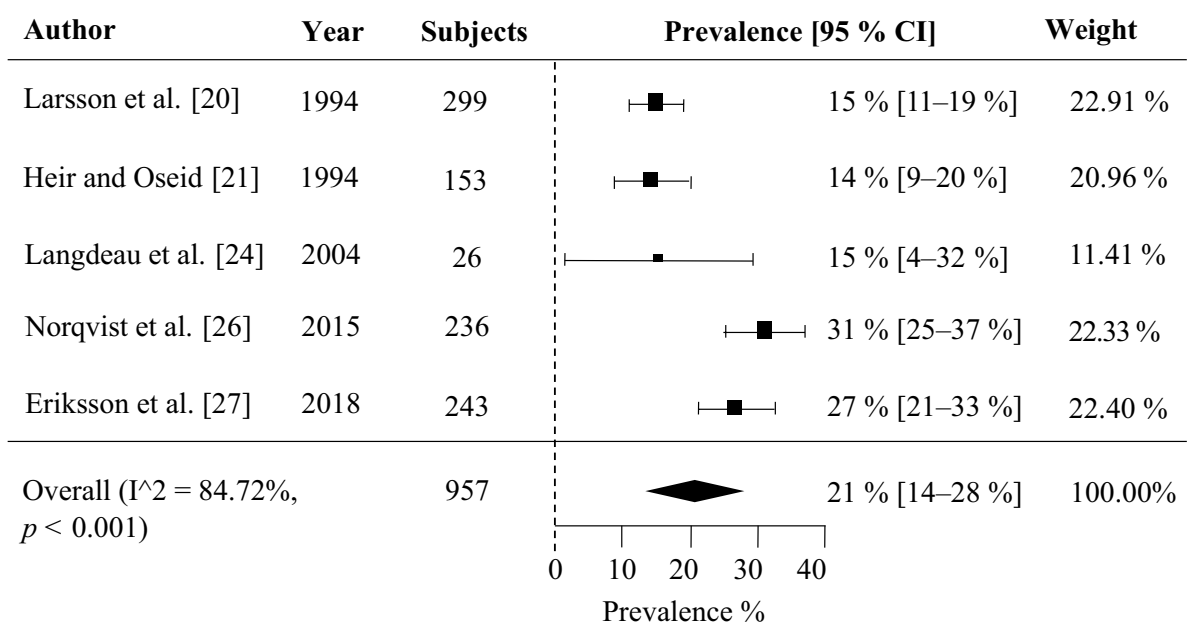

Canada, including cross-country skiers and biathletes, as part of a larger study. They reported a prevalence of $20 \%$ of physician-diagnosed asthma based on lung function measures in 44 skiers (Table 2).

\subsubsection{Studies reporting prevalence of asthma based on combined criteria of previous physician-diagnosed asthma or current lung function measures}

In three studies, the criteria for asthma were a combination of either having a previous physician-diagnosed asthma or having asthma-like findings in current lung function test [19, $22,23,25]$ (Table 3). The mean prevalence of asthma in these four studies was $28 \%$ (CI 95\% 13-46\%) and is presented in Fig. 3.

\subsection{Possible underdiagnosis of asthma among skiers}

Several studies have revealed the possibility of asthma being underdiagnosed in skiers. Previously healthy skiers without a prior asthma diagnosis or medication use were found to fulfill diagnostic criteria of asthma according to lung function tests. There seems to be a decreasing trend in the prevalence of undiagnosed asthma in previously healthy skiers, as it decreased from 55 to $20 \%$ from 1993-2010, excluding the data from the most recent and relatively small study of 13 subjects [19, 29, 32, 33, 35, 36].

Larsson et al. [19] conducted a study in 1993 in 42 crosscountry skiers, where asthma was diagnosed based on positive methacholine challenge test results and the presence of at least two asthma symptoms. Thirty-four percent of the previously healthy skiers fulfilled the diagnostic criteria used. In a later study conducted by Sue-Chu et al. in 1999
[28], 40\% (12/30) of previously healthy skiers were considered to have ski asthma. In this study, the diagnosis was also defined as positive methacholine challenge test results and the presence of asthma-like symptoms.

A field exercise challenge was used as the diagnostic test by Ogston and Butcher [32]. They found that 31\% (20/91) of the unmedicated high school skiers had exercise-induced bronchoconstriction [32]. A Finnish study by Pohjantähti and others [33] reported that 35\% (7/20) of the previously healthy skiers had a decrease in FEV 1 by $\geq 10 \%$, a decrease in MMEF (maximal mid-expiratory flow) by $\geq 20 \%$ or a decrease in both (2 FEV1, 7 MMEF) with a similar challenge.

In 2010, Sue-Chu et al. [35] compared different diagnostic tests and observed that a total of $25 \%(12 / 48)$ of the previously healthy skiers had bronchial hyperresponsiveness in either the methacholine challenge test or EVH (eucapnic voluntary hyperpnoea) test and fulfilled the criteria for therapeutic use exemption (TUE) at that time.

A British multisport study conducted by Dickinson et al. [36] showed that $62 \%$ (8/13) of the biathletes included were previously healthy but had bronchial hyperresponsiveness in the EVH test.

\subsection{Risk factors and onset age of asthma or asthma-related symptoms}

There is only one study assessing possible risk factors of developing asthma among competitive skiers. Eklund and colleagues reported among 244 skiers from a high school population that family history of asthma and nasal allergy were significant risk factors for asthma both among competitive skiers and non-skiers [27]. It seemed that allergy was not as significant risk factor among skiers as it is among non-skiers. 


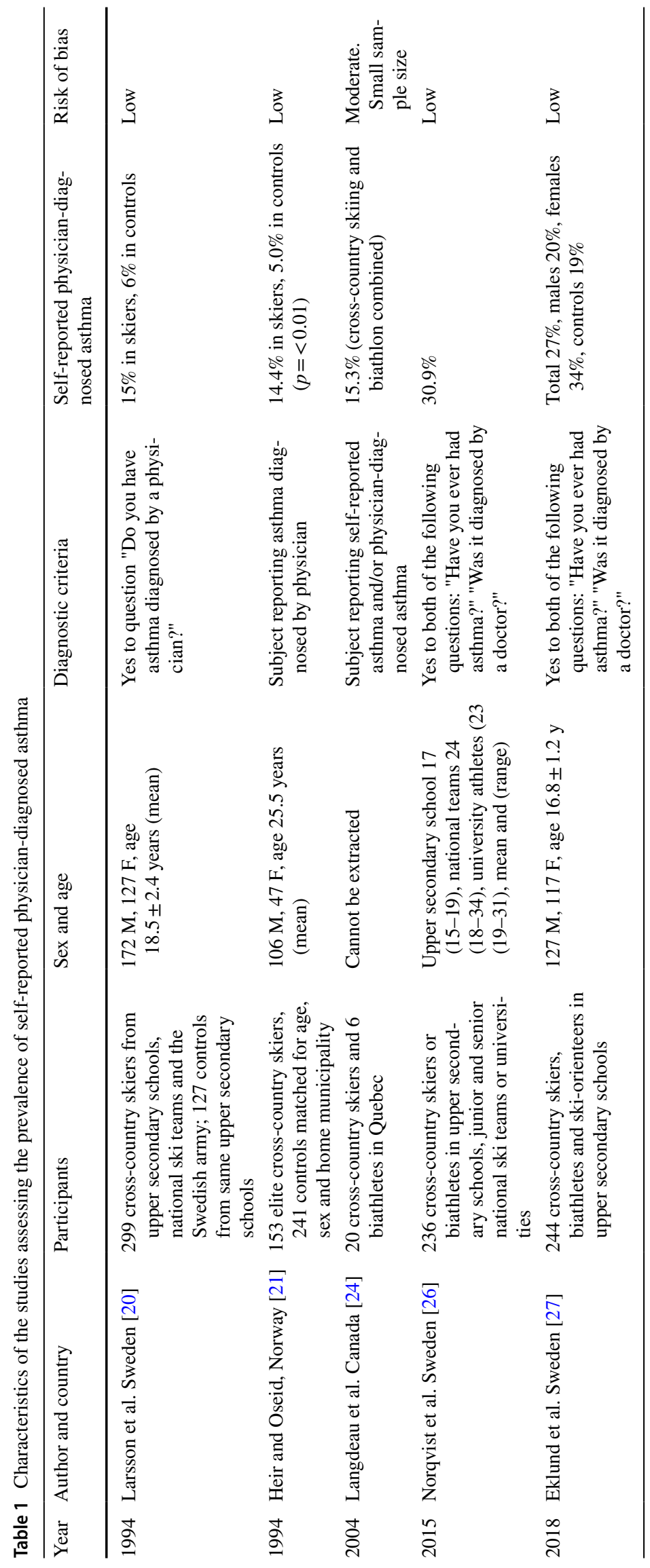


The age of asthma onset in skiers has been studied in Norway and Sweden in four different studies [19, 21, 26, 27]. The onset age varied from early adolescence to early adulthood, and the onset occurred at a later age in the skiers than in the controls.

Eklund et al. [27] compared junior elite cross-country skiers, biathletes and ski-orienteers to controls in upper secondary schools in Sweden. The median age at onset of asthma in the skier group was significantly higher than that in the controls ( 12 vs. 8 years, $p<0.001)$. the onset age of asthma was distributed evenly from birth into adolescence in the control group and was concentrated to the 10-15-year-old age range in the skier group. The mean age of the skiers was $16.8 \pm 1.2$ years.

In another Swedish study conducted by Norqvist et al. [26], the onset age of asthma in both skiers in the 15-19-year-old group and those in the 20-34-year-old group was mostly in early adolescence.

In a study by Heir and Oseid [21], 16 of 22 skiers with self-reported symptoms recalled their onset age of asthma. Fifteen skiers reported an onset age in late adolescence or early adulthood. Only one skier reported the onset of asthma in early childhood. Moreover, Larsson et al. [19] reported that none of the 42 skiers with asthma in their study recalled their onset age of asthma to be during childhood.

\subsection{Use of asthma medication among skiers}

Six studies reported the use of asthma medication among skiers. Asthma medication use was defined as the use of one or more of the following medications: inhaled bronchodilators ( $\beta_{2}$-agonists or anticholinergic agents), inhaled anti-inflammatories (corticosteroids, cromoglycates), oral theophylline or corticosteroids (Fig. 4, Table 4). The prevalence of asthma medication use in skiers was on average 23\% (CI 95\% 19-26\%) across six studies with 1146 subjects.

\subsection{Asthma-related pathophysiological features in skiers}

\subsubsection{Airway inflammation}

Airway inflammation in skiers with or without asthma has been investigated using bronchial biopsies in three studies $[14,15,28]$, using induced sputum in one study [28] and using exhaled nitric oxide in three studies [29, 37, 39].

The results of the six studies assessing airway inflammation in skiers are summarized in Table 5. In short, studies using bronchial biopsies have demonstrated increased numbers of lymphoid aggregates and inflammatory cells in bronchial mucosa or bronchoalveolar lavage fluid in skiers, most of whom can be considered asthmatic skiers, compared to healthy controls, but these findings were not as marked 


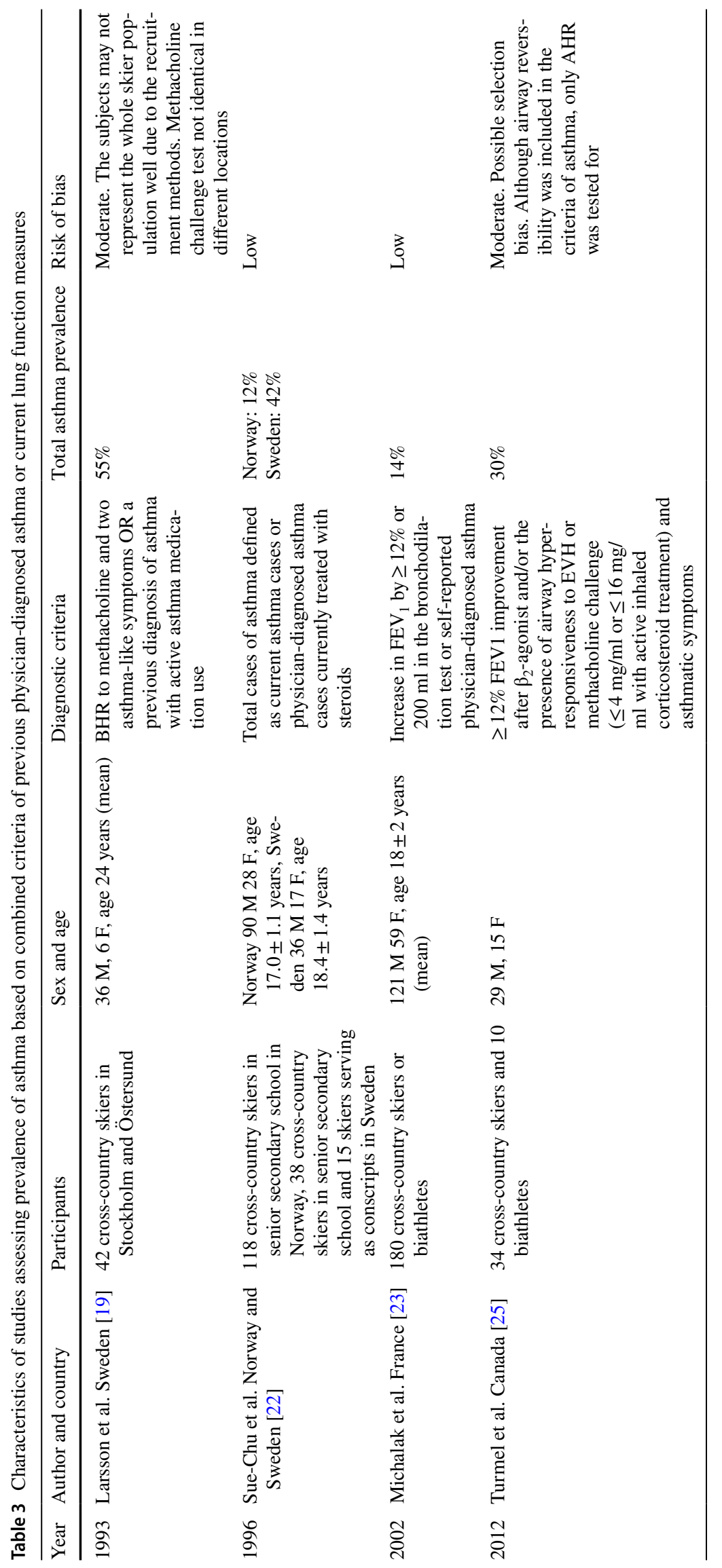


Fig. 3 Total asthma prevalence from three studies is $28 \%$ in 437 subjects
Asthma based on combined criteria

\begin{tabular}{|c|c|c|c|c|c|}
\hline \multirow{2}{*}{$\begin{array}{l}\text { Author } \\
\text { Larsson et al. [19] }\end{array}$} & \multirow{2}{*}{$\frac{\text { Year }}{1993}$} & Subjects & \multicolumn{2}{|c|}{ Prevalence $[95 \%$ CI] } & \multirow{2}{*}{$\begin{array}{l}\text { Weight } \\
23.37 \%\end{array}$} \\
\hline & & 42 & $\longmapsto$ & $55 \%[39-70 \%]$ & \\
\hline Sue-Chu et al. [22] & 1996 & 171 & $H-1$ & $21 \%[15-28 \%]$ & $26.52 \%$ \\
\hline Michalak et al. [23] & 2002 & 180 & 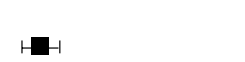 & $14 \%[10-20 \%]$ & $26.58 \%$ \\
\hline Turmel et al. [25] & 2012 & 44 & $\longmapsto$ & $30 \%[17-44 \%]$ & $23.53 \%$ \\
\hline \multicolumn{2}{|c|}{$\begin{array}{l}\text { Overall }\left(\mathrm{I}^{\wedge} 2=92.35 \%\right. \\
p<0.001)\end{array}$} & 437 & & $28 \%[13-46 \%]$ & $100.00 \%$ \\
\hline & & & $\begin{array}{ccc} & 1 & \mid \\
20 & 40 & 60\end{array}$ & 80 & \\
\hline
\end{tabular}
medication use in six studies with 1146 subjects
Asthma medication use

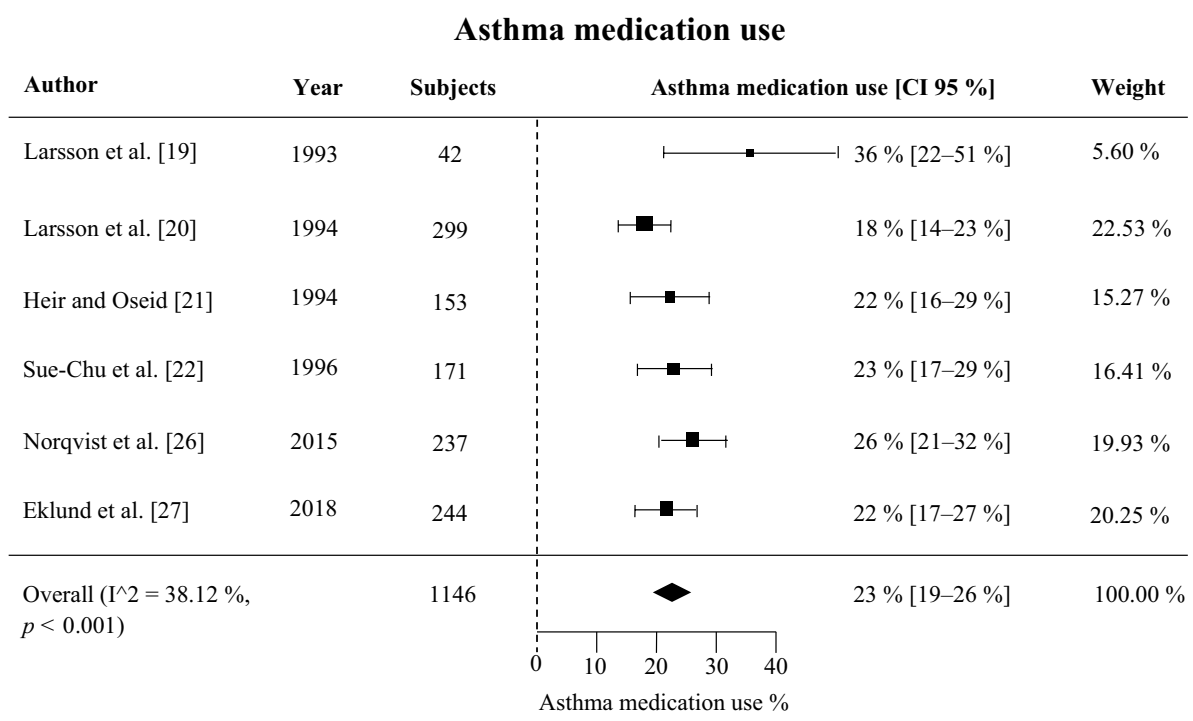

as those occurring in non-skiing asthmatic controls. However, the exhaled nitric oxide and inflammatory markers in induced sputum were not different between the asthmatic skiers and healthy controls.

\subsubsection{Seasonal variation in bronchial reactivity or airway inflammation}

Norwegian cross-country skiers and controls were followed for 1 year to assess the seasonal changes in bronchial reactivity and respiratory tract infections during their mandatory military service [40-42]. There were no differences in lung function between the groups or changes in lung function during the study period. Provocative doses in the methacholine test (10\% reduction in FEV1) decreased during the winter (i.e., increase in bronchial responsiveness) but increased again towards the summer. The methacholine test was also conducted when a subject had a respiratory infection. Among the skiers, the provocative dose decreased significantly after a respiratory infection, whereas in controls it did not. The provocative dose in skiers did not return to baseline values until six weeks after infection [40-42].

Kennedy et al. 2016 [38] followed eighteen female skiers for one season, performed an analysis of induced sputum and used the Leicester Cough Questionnaire (LCQ). Measurements were conducted three times during the season: at the beginning and end of the training season and during the competition season. No changes in induced sputum cell counts or LCQ were observed between the measurements in the training season, but there was a significant increase in the amounts of lymphocytes and eosinophils in induced sputum from the first to third measurements $\left(0.17\right.$ vs. $0.55 \times 10^{6} 1 / \mathrm{g}$, 0.014 vs. $\left.0.104 \times 10^{6} 1 / \mathrm{g}, p<0.05\right)$ [38]. 


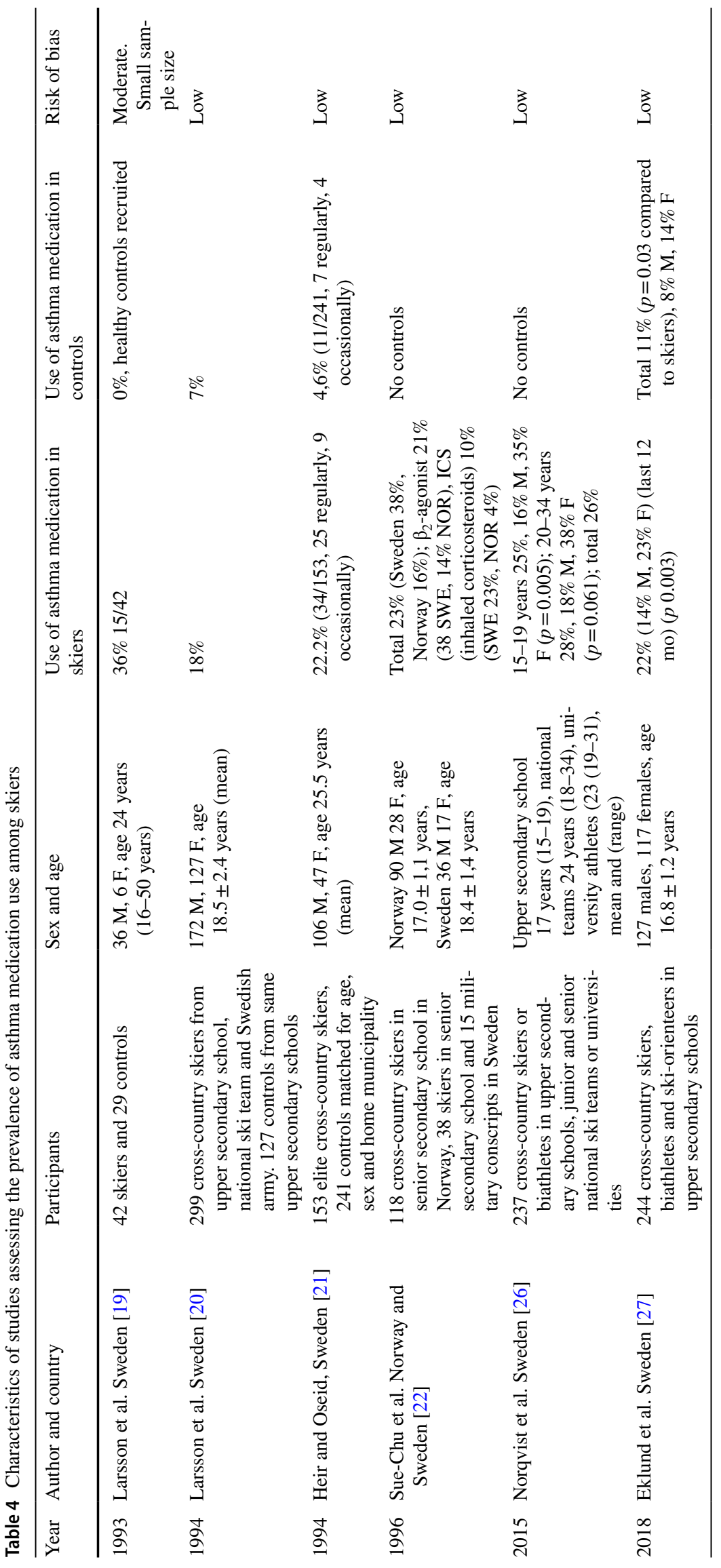




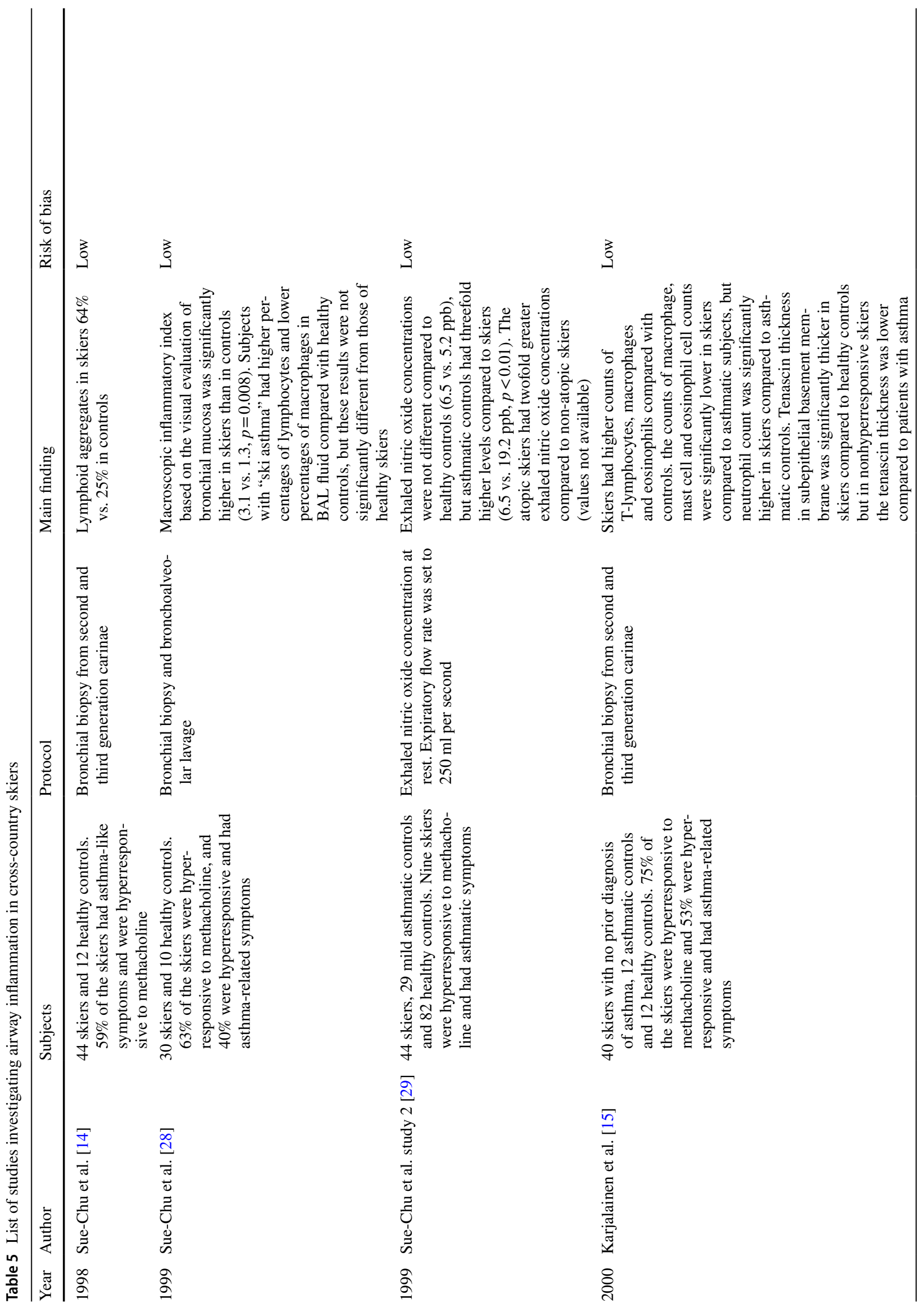




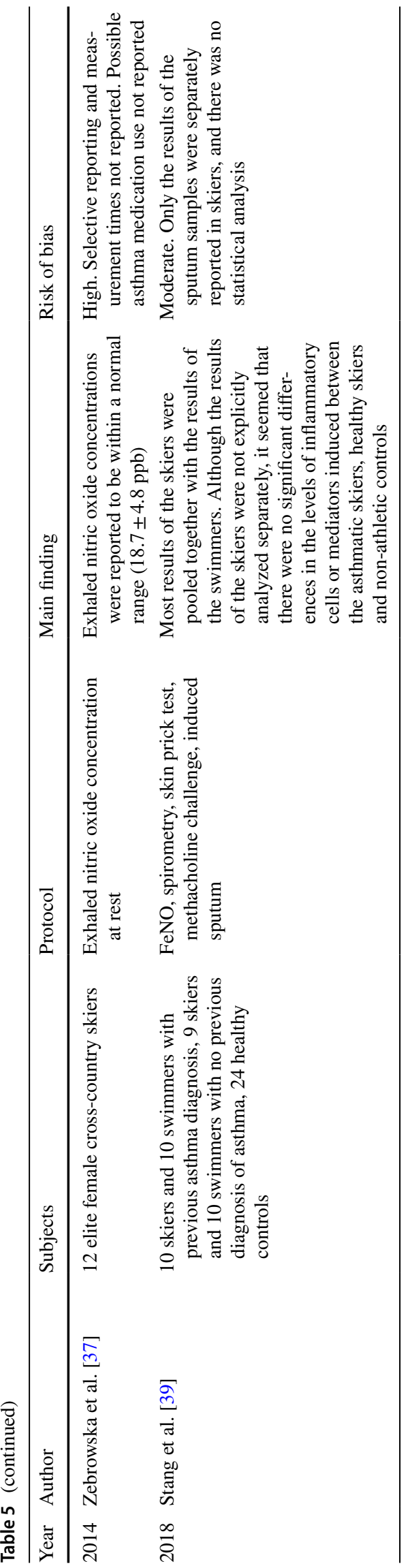

\subsection{Effect of anti-asthmatic treatment in non-asthmatic and asthmatic skiers}

There were two studies investigating the effect of bronchodilators on lung function and exercise performance in skiers $[43,44]$ and one assessing the effect of anti-inflammatory treatment [30].

Sandsund and others 1998 [43] studied salbutamol exclusively in cross-country skiers. Eight male skiers completed two exercise tests in a climatic chamber set to $-15^{\circ} \mathrm{C}$ after the inhalation of salbutamol $(3 \times 400 \mu \mathrm{g})$ or a placebo. Three skiers were using anti-asthmatic medication but had not been diagnosed with asthma. The withdrawal of medication before the test was not reported. $\mathrm{FEV}_{1}$ increased significantly after the inhalation of salbutamol before the test and was higher during the test compared to the levels with the placebo at all six time points. No significant changes were observed in maximal oxygen uptake or blood lactate levels, and salbutamol did not have performance-enhancing effects.

In 1999, Sue-Chu et al. [44] investigated the effect of salmeterol on physical performance on a treadmill in a climatic chamber in eight healthy male cross-country skiers at $-15^{\circ} \mathrm{C}$. The inhalation of $50 \mu \mathrm{g}$ salmeterol significantly improved the FEV1 level before, during, and after the exercise test but did not have an effect on the time to exhaustion (392.5 s with salmeterol vs. $395.6 \mathrm{~s}$ with the placebo, $p=0.84$ ).

Sue-Chu et al. [30] studied the budesonide treatment over a 22 -week period in 25 cross-country skiers who had'ski asthma' (i.e., two or more asthma-like symptoms, including wheezing and abnormal breathlessness or chest tightness upon exertion, at rest, or upon exposure to irritants and BHR to methacholine) and had not used anti-asthmatic medication. They demonstrated no significant improvement in lung function, airway inflammation or tenascin expression.

\subsection{Other asthma-related studies in cross-country skiers}

There were three studies comparing skiers' bronchial reactivity in different diagnostic tests [31, 34, 35], one study comparing self-reported symptoms to bronchial hyperresponsiveness [56] and one study reporting the longitudinal follow-up study in three cross-country skiers [45]. The studies are represented in Table 6.

In short, three studies [31, 34, 35] assessed the prevalence of BHR among skiers using different tests. There was marked variation in the proportion of subjects having positive test results using different protocols. Stenfors reported that the self-reported symptoms have poor diagnostic accuracy in predicting BHR [56]. The longitudinal case study by Verges and others showed variable signs of airway obstruction in three skiers [45]. 


\subsection{Risk of bias}

The risk of bias in the selected articles was assessed by the Cochrane risk of bias tool. Among the 33 articles that were included in the synthesis, 19 articles were considered to have a low risk of bias, 9 articles were considered to have a moderate risk of bias, and 3 articles were considered to have a high risk of bias. Two articles were excluded from the review process due to a very high risk of bias and unclear reporting [65, 66]. See electronic Supplementary File 2 for details.

\section{Discussion}

The aim of this review was to establish an overview of the current literature on asthma in competitive cross-country skiers. Cross-country skiing, nordic combined and biathlon are the only Olympic endurance sports that take place outdoors in possible subfreezing temperatures. A high ventilation rate and large amounts of inhaled cold and dry air leads to extremely high demands on lung function and may cause epithelial damage.

\subsection{Prevalence of asthma, asthmatic symptoms and use of asthma medication among skiers}

Among cross-country skiers, the mean prevalence of selfreported physician-diagnosed asthma was $21 \%$, and for a combination of self-reported physician-diagnosed asthma and asthma based on lung function measures was $28 \%$, and that for objectively verified asthma was 20\% [19-27]. These values are considerably higher than the prevalence of asthma in the general population, which is approximately $10 \%$ [4, 5]. Three of the studies also included controls who did not engage in competitive sports, and the prevalence of asthma was significantly higher in cross-country skiers [20, 21, 27].

About $10 \%$ of people in the general population are diagnosed with asthma, and it has been estimated that approximately another 5-10\% have asthma-like symptoms [6]. According to the current review, the prevalence of at least one asthma-like symptom among competitive cross-country skiers was high and varied between 22 and $84 \%$. However, it is important to note that asthma-like symptoms as such are often not related to asthma [56]. In studies where at least two symptoms were required to be considered asthma-like, the highest prevalence was 51\% [22]. In all three studies that compared the difference between cross-country skiers and controls, the prevalence of asthma-like symptoms was higher in skiers [20, 21, 27].

The high prevalence of asthma among competitive skiers is probably not only related to the sport but also cold air exposure and high ventilatory demand, since the prevalence of asthma varies between sports with high and low ventilatory demand [8].

The relative frequency of diagnosed asthma to that of asthmatic symptoms without a formal diagnosis is partly related to the responsibility of health care professionals to suspect asthma and conduct diagnostic testing in symptomatic subjects. If there is a high threshold for suspecting and testing for asthma, asthma may be underdiagnosed, and a high proportion of subjects with asthma suffer from symptoms without proper a diagnosis and medication. The prevalence of asthma-related symptoms relative to the prevalence of asthma differed across the studies included in this review. In three studies, the number of symptomatic skiers was higher than that of asthmatic skiers [21, 22, 25], but in two more recent studies, there were more asthmatic skiers than skiers with asthma-related symptoms without a diagnosis of asthma [26, 27]. Furthermore, in many studies, a large share of previously healthy skiers had variable airway obstruction compatible with asthma, and this proportion was higher in earlier studies and lower in more recent studies [19, 32, 33, 35, 36, 44]. Together, these results suggest that asthma has been underdiagnosed but that this problem has diminished according to the latest studies, possibly due to increased general awareness of asthma among skiers. In most of the studies, the criteria for asthma used with the different lung function tests were based on international guidelines or common practice, but not all criteria were based on these guidelines or common practice (e.g., changes in MMEF after exercise). There are no studies discussing possible overdiagnosis of asthma in cross-country skiers. It is important to note that symptoms as such are not reliable predictors of airway hyperresponsiveness and asthma [56]. In studies reporting self-reported physician-diagnosed asthma it is not clear if objective measures had been used to diagnose asthma or if the diagnosis was based on symptoms only.

The prevalence of asthma medication use was $23 \%$ in 1146 skiers across six studies. The proportion of competitive skiers reporting the use of asthma medication is in accordance with the reported prevalence of asthma in this population. Based on these results, it can be cautiously stated that there is no evidence for the misuse of asthma medication in skiers. However, based on all the studies included, it cannot be concluded whether the subjects with a diagnosis of asthma and the subjects using asthma medication were the same subjects. In addition, the use of asthma medication is based on self-reports only. Of the studies in this review, only Heir and Oseid [21] reported the use of asthma medication among skiers without a diagnosis of asthma, and they found that nine percent of athletes with no asthma diagnosis used asthma medication.

The use of asthma medication among competitive skiers has been a controversial topic and widely discussed in media. The use of corticosteroids is now allowed and also 


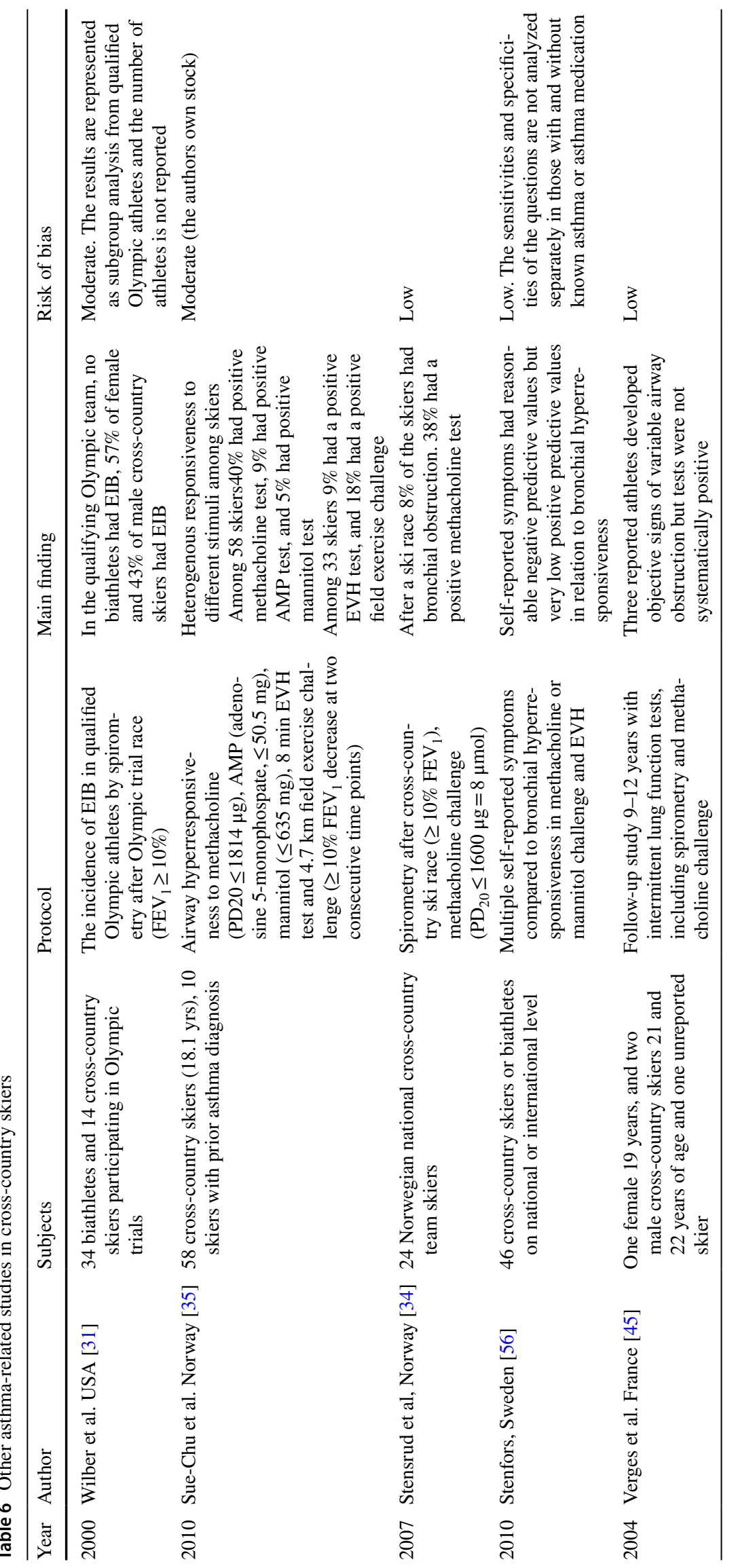


the use of several bronchodilators is allowed in up to relatively high doses (salbutamol $1600 \mathrm{ug}$ over $24 \mathrm{~h}$ period and $800 \mathrm{ug}$ over $12 \mathrm{~h}$ period, formoterol 54 ug over $24 \mathrm{~h}$, salmeterol 200 ug over $24 \mathrm{~h}$ ) [60]. We identified two studies in which the effects of a relatively high dose of a short-acting $\beta_{2}$-agonist (salbutamol) or a normal therapeutic dose of a long-acting $\beta_{2}$-agonist (salmeterol) on lung function and exercise capacity were studied in healthy skiers or skiers with treated asthma [43, 44]. Interestingly, exercise capacity was not affected by these bronchodilators in either of the studies, although lung function was mildly improved, as expected. These results suggest that occasional use of bronchodilators in normal therapeutic doses does not improve exercise capacity, but it is beneficial in preventing bronchoconstriction in skiers with asthma. However, high oral doses of salbutamol or a combination of inhaled $\beta_{2}$-agonists improved sprinting capacity or maximal strength in two studies $[47,48]$ acutely and in longitudinal use. It remains to be studied whether these kinds of improvements in strength may benefit healthy cross-country skiers to improve, for example, their final sprint performance. Moreover, there is a lack of research investigating the longitudinal effects of bronchodilators on exercise performance apart from previously mentioned study by Hostrup and others [47].

\subsection{Mechanisms of asthma in skiers}

There are only a few studies on the cellular and inflammatory mechanisms of asthma among skiers. In general, skiers had higher levels of inflammatory cells in their airways than did healthy non-skiers. Interestingly, inflammatory changes were observed in the airways of both asthmatic and nonasthmatic skiers, and the level of eosinophils was higher in non-skiers with asthma than in skiers with asthma. The exhaled nitric oxide concentration, an inflammatory biomarker associated with eosinophilic inflammation in individuals with asthma, was not different between skiers and healthy controls and was lower in the skiers than in asthmatic controls. Taken together, these results suggest that the distribution of inflammatory endotypes may differ between skiers and non-skiers with asthma that eosinophilic inflammation may not be as prevalent in skiers with asthma and that skiing even in the absence of asthma may trigger noneosinophilic inflammation.

Asthma is usually associated with chronic airway inflammation [1]. Currently, asthma is divided into different endotypes based on the underlying inflammatory mechanisms. The most frequent inflammatory endotypes include allergic eosinophilic asthma, non-allergic eosinophilic asthma, neutrophilic asthma and pauci-granulocytic asthma [49]. In all subjects, whether they have asthma or not, an increase in minute ventilation and dryness of the inhaled air increases the loss of water from epithelial lining fluid (ELF) covering the airway mucosa, making it hypertonic. Mast cells and other inflammatory cells are present in the airways of people with asthma, and they are activated to excrete inflammatory mediators, such as histamine and leukotrienes, in a hypertonic environment. This so-called osmotic mechanism is thought to trigger airway obstruction in asthmatic people during or after exercise $[13,50]$.

Neutrophilic inflammation in asthma is associated with different irritating stimuli [51], and exposure to cold air is reported to increase airway neutrophilia in people with asthma [52]. Since skiers compete and train in cold conditions and cold air has a very low absolute humidity, their airways are repeatedly exposed to a loss of water and increased osmolality of the epithelial lining fluid. This repeated exposure to high ventilation rates in cold air may, in addition to triggering airway obstruction in people with established asthma, cause irritation and low-grade chronic inflammation and thereby induce asthma in skiers. This idea is also supported by the findings that bronchial hyperresponsiveness and the number of inflammatory cells in airways increase among skiers during the winter [38, 40]. It is important to note that airway infections increased bronchial responsiveness in skiers contrary to healthy controls [41].

The age at onset of asthma is associated with the inflammatory mechanism underlying asthma. Allergic eosinophilic asthma often begins in childhood or early adulthood, while non-allergic eosinophilic and noneosinophilic endotypes more often begin in adulthood [49]. As asthma is a relatively common disease in the general population, some skiers with asthma have likely developed asthma even if they had never started skiing, but some of the skiers may have true skiing-induced asthma. As the onset age of asthma was higher among skiers than among non-skiers with asthma [27] and in one study, none of the skiers reported the onset of asthma in early childhood [19], the prevalence of allergic eosinophilic asthma may be lower among skiers than among non-skiers with asthma. This concept is logical, since children who are diagnosed with allergic asthma during childhood are probably less likely to engage in sports at the competitive level and start an active career as a skier. On the other hand, once young people start actively training and competing in cross-country skiing, they may be at a higher risk of developing asthma due to repeated airway irritation with cold air exposure. The fact that allergic asthma is eosinophilic and asthma induced by irritation is more often neutrophilic can partly explain why asthma in skiers in the existing studies was associated more strongly with neutrophilic than eosinophilic inflammation. The relatively higher neutrophilic activity in skiers with asthma may also have treatment-related consequences, since anti-inflammatory treatment with inhaled glucocorticoids is most effective in people with asthma and eosinophilic inflammation [53-55]. In fact, this concept is in line with the results of a study that 
assessed the effect of inhaled budesonide on ski asthma and found no improvement in lung function or airway inflammation [30].

\subsection{Detecting asthma in skiers}

Due to the high prevalence of asthma among competitive skiers, asthma should be actively screened. Since selfreported symptoms are not a very reliable predictor of asthma-like reversible or variable airway obstruction among skiers [56], objective measures of lung function are needed. In general, tests of bronchial hyperresponsiveness seem to be more sensitive tools in detecting asthma than spirometry with bronchodilation. Based on two studies [34, 35], the tests used to detect hyperresponsiveness in order of the highest to the lowest level of sensitivity are as follows: the methacholine challenge, exercise test, EVH test, AMP challenge and mannitol challenge. Of these tests, the methacholine test acts directly on muscarinic receptors in bronchial smooth muscle, whereas the other tests are indirect and cause airway obstruction by increasing the tonicity of epithelial lining fluid, which triggers inflammatory cells to release mediators that activate smooth muscle [2]. It is understandable that direct tests of hyperresponsiveness, such as the methacholine challenge, are more sensitive than indirect tests, because the latter tests are dependent on the presence and activity of inflammatory cells in airways. However, it is important to note that the sensitivity and specificity of each of these tests is dependent on the threshold used (e.g., the provocative dose of methacholine or the level of decrease in $\mathrm{FEV}_{1}$ in exercise challenge). EVH test is usually considered more sensitive than the exercise test in detecting hyperresponsiveness [57]. The opposite finding in skiers in one study may be related to the fact that top athletes may be able to achieve even higher minute ventilation in their own sport than in the EVH test with a predefined level of minute ventilation.

The onset and severity of asthma-related symptoms may progress gradually, and athletes may not be able to differentiate asthma-related symptoms from normal breathlessness and exhaustion. Therefore, it may be useful to conduct regular screenings of asthma to promote athletes' health. This would decrease the probability of athletes training and competing with asthma that they are not aware of. On the other hand, regular screening of asthma requires resources and there is no universal agreement over the correct criteria of asthma in athletes. A single positive test result in a direct bronchial challenge with no asthma-related symptoms may not indicate asthma and needs further verification in indirect challenges, since healthy people, especially cross-country skiers, may have increased bronchial responsiveness during the winter season, as shown in the study by Heir [40]. A positive test result in an indirect bronchial challenge, such as the exercise challenge, with no asthma-related symptoms may, however, be indicative of asthma, because people have a measurable level of obstruction in real-life conditions, which affect exercise performance. Regardless of whether the lung function test is used, it is worth considering that due to the lack of a gold standard in asthma diagnostics, all the diagnostic cut-off values are somewhat controversial and are based on studies in non-athletes. Whether different cut-off values are needed for skiers or other competitive athletes is not known.

Exercise-induced laryngeal obstruction (EILO) is a transient, reversible and inappropriate narrowing of the larynx in response to exercise [58]. In contrast to exerciseinduced asthma, the symptoms in EILO peak during exercise, whereas the symptoms in exercise-induced asthma may worsen after exercise. There is one study assessing the prevalence of EILO in a retrospective cohort by Nielsen and others [61]. EILO was found in 35.2\% $(n=31)$ of the studied athletes and asthma was concurrently present in $38.7 \%$ $(n=12)$ in athletes with EILO. Since asthma and laryngeal obstruction may coexist $[59,61]$, it is important to remember that exercise-induced symptoms in an individual treated for asthma may not be due to bronchial obstruction but rather due to untreated laryngeal problems.

\subsection{Strengths and limitations of the review}

This review is based on a systematic literature search focusing on all aspects of asthma in competitive cross-country skiers, and all the major databases were searched without restrictions. The number of studies identified and included was relatively small, and each topic was often covered by only a few studies with considerable differences in aspects of the studies, such as the methods, definitions, and cut-off levels. One common problem among skiers and a possible confounder in all asthma-related research is repeated respiratory infections. Intensive training in cold conditions, a high level of stress frequent travelling and mass gatherings in sports increase the risk for infection and symptoms suggestive of asthma. In fact, one of the studies that assessed bronchial responsiveness among skiers reported increased bronchial responsiveness after an airway infection in skiers but not in controls [41].

Studies included in the review were published between 1993 and 2018. During this time, the understanding of asthma pathophysiology has increased, and the diagnostic methods and criteria have been standardized. Moreover, the treatment of asthma and doping regulations have evolved based on new knowledge. Thus, the methods and research questions have also evolved during this time period.

In our risk of bias assessment, $10 \%$ of the articles were considered to have moderate or high risk of bias, and this result should also be taken into account.

The meta-analysis was based on the eight available publications on the prevalence of asthma and use of asthma 
medication. The relatively small number of published studies decreases the reliability of the results and makes it challenging to use formal publication bias assessment. The methods assessing possible publication bias usually require more than ten articles to be included in the meta-analysis due to heterogeneity and low power [64]. We used random effects model in the meta-analysis. However, the number of studies was small and this may affect the reliability of significance testing, as the small number of studies undermines the accuracy of the estimate of the between-study variance, standard error of the estimated prevalences and thereby ultimately the significance testing.

\section{Conclusions and future directions}

Based on the current literature, asthma and asthma-like symptoms are highly prevalent among competitive crosscountry skiers. In lung function tests many previously healthy skiers have bronchial hyperresponsiveness compatible with asthma, i.e., asthma is possibly underdiagnosed in this population. Systematic screening for asthma with objective tests for bronchial hyperresponsiveness is thus warranted in competitive skiers. There is also a need for international consensus over the criteria of asthma and its treatment in athletes. The self-reported use of asthma medication is not more frequent than the diagnosis of asthma among skiers, suggesting that there is currently no remarkable overuse of asthma medication in this group. The mechanisms of asthma is more often related to neutrophilic inflammation in skiers than in other people with asthma, and this result may be related to a lower prevalence of early-onset allergic asthma (negative selection since small children with asthma are less likely begin an active skiing career) and neutrophilic inflammation induced by repetitive exposure to cold dry air and a high ventilatory demand. According to one study, there is an indication that inhaled glucocorticoids may not be as effective in treating skiers' asthma as it is in treating asthma in general, and this result is in accordance with the previous conclusion that inhaled corticosteroids are most effective in treating eosinophilic asthma.

Future research should focus on the role of the intensity of training and repeated airway infections on the development of asthma among competitive skiers. The optimal treatment, current asthma control and natural course of asthma are not known in this population. Currently, there is also no information on how asthma among competitive skiers affects their ability to train, participate in competitions and succeed in their career.

Acknowledgements The authors thank Saila Huuskonen for her assistance in the literature search and Heini Huhtala and Tuomas Karvonen for their help in conducting the meta-analyses.
Author contributions All authors designed the review, designed the literature search and approved the final manuscript. RM-H conducted the literature search, screened the search results, extracted the data from selected articles, conducted risk of bias analysis, conducted the analyses of results and wrote the first version of the manuscript. JK and LL screened the search results, verified the extracted data from selected articles, conducted the risk of bias analysis, participated in the analysis of the results and manuscript writing. JP and MV participated in designing the study and writing the manuscript.

\section{Compliance with Ethical Standards}

Funding The study was supported by the Tampere Tuberculosis Foundation.

Conflicts of interest Mr Mäki-Heikkilä declares receiving financial support from Tampere Tuberculosis Foundation and Tampere University to author this publication. Dr Karjalainen declares receiving grant from Tampere Tuberculosis Foundation, fees for consulting from Boehringer Ingelheim, Finnish Center for Integrity in Sports, GlaxoSmithKline, Merck Sharp \& Dohme, Novartis and Teva and payments for lectures from ALK, AstraZeneca, Chiesi, Boehringer Ingelheim, GlaxoSmithKline, Leo Pharma, Mundipharma, Novartis and Orion Pharma. Dr Parkkari declares no conflicts of interest. Dr Valtonen declares employment for acting as team doctor for Finnish Ski Association via KIHU - Research Institute for Olympic Sports. Dr Lehtimäki declares having received fees for consulting from ALK, AstraZeneca, Boehringer Ingelheim, Chiesi, GSK, Orion Pharma, Mundipharma, Novartis, SanofiGenzyme and Teva, and payments for lectures from AstraZeneca, Boehringer Ingelheim, Chiesi, Circassia, GSK, Orion Pharma, Mundipharma, Novartis, SanofiGenzyme and Teva.

Data availability statement The search syntax used in this review is available as Supplemental file 1, the detailed risk of bias assessment is available as Supplemental file 2 and the full-text search with exclusion reasons is available as Supplemental file 3. The data extraction table is available from authors on reasonable request.

Open Access This article is licensed under a Creative Commons Attribution 4.0 International License, which permits use, sharing, adaptation, distribution and reproduction in any medium or format, as long as you give appropriate credit to the original author(s) and the source, provide a link to the Creative Commons licence, and indicate if changes were made. The images or other third party material in this article are included in the article's Creative Commons licence, unless indicated otherwise in a credit line to the material. If material is not included in the article's Creative Commons licence and your intended use is not permitted by statutory regulation or exceeds the permitted use, you will need to obtain permission directly from the copyright holder. To view a copy of this licence, visit http://creativecommons.org/licenses/by/4.0/.

\section{References}

1. Global Strategy for Asthma Management and Prevention, 2018.

2. Coates AL, Wanger J, Cockcroft DW, et al. ERS technical standard on bronchial challenge testing: general considerations and performance of methacholine challenge tests. Eur Respir J. 2017. https ://doi.org/10.1183/13993003.01526-2016.

3. Hallstrand TS, Leuppi JD, Joos G, et al. ERS technical standard on bronchial challenge testing: pathophysiology and methodology of indirect airway challenge testing. Eur Respir J. 2018. https:// doi.org/10.1183/13993003.01033-2018. 
4. To T, Stanojevic S, Moores G, et al. Global asthma prevalence in adults: findings from the cross-sectional world health survey. BMC Public Health. 2012;12(1):204. https://doi. org/10.1186/1471-2458-12-204.

5. Honkamäki J, Hisinger-Mölkänen H, Ilmarinen P, et al. Age- and gender-specific incidence of new asthma diagnosis from childhood to late adulthood. Respir Med. 2019;154:56-62. https://doi. org/10.1016/j.rmed.2019.06.003

6. Borna E, Nwaru BI, Bjerg A, et al. Changes in the prevalence of asthma and respiratory symptoms in western Sweden between 2008 and 2016. Allergy. 2019. https://doi.org/10.1111/all.13840.

7. Chu LM, Pahwa P. Prevalence and associated factors for selfreported asthma in a Canadian population: the Canadian Community Health Survey, 2014. J Asthma. 2018;55(1):26-34. https ://doi.org/10.1080/02770903.2017.1310228.

8. Selge C, Thomas S, Nowak D, Radon K, Wolfarth B. Asthma prevalence in German Olympic athletes: a comparison of winter and summer sport disciplines. Respir Med. 2016;118:15-211. https://doi.org/10.1016/j.rmed.2016.07.008.

9. Fitch KD. An overview of asthma and airway hyper-responsiveness in Olympic athletes. Br J SPORTS Med. 2012;46(6):413-6. https://doi.org/10.1136/bjsports-2011-090814.

10. Sandbakk O, Holmberg HC. A reappraisal of success factors for Olympic cross-country skiing. Int J SPORTS Physiol Perform. 2014;9(1):117-21. https://doi.org/10.1123/IJSPP.2013-0373.

11. Holmberg H-C, Rosdahl H, Svedenhag J. Lung function, arterial saturation and oxygen uptake in elite cross country skiers: influence of exercise mode. Scand J Med Sci SPORTS. 2007;17(4):437-44. https://doi.org/10.111 1/j.1600-0838.2006.00592.x.

12. THE INTERNATIONAL SKI COMPETITION RULES (ICR). https://assets.fis-ski.com/image/upload/v1570528214/fis-prod/ assets/ICR_CrossCountry_2019clean.pdf. Accessed 23 Oct 2019.

13. Anderson SD, Daviskas E. The mechanism of exercise-induced asthma is. J Allergy Clin Immunol. 2000;106(3):453-9. https:// doi.org/10.1067/mai.2000.109822.

14. Sue-Chu M, Karjalainen EM, Altraja A, et al. Lymphoid aggregates in endobronchial biopsies from young elite cross-country skiers. Am J Respir Crit Care Med. 1998;158(2):597-601. https ://doi.org/10.1164/ajrccm.158.2.9711012.

15. Karjalainen EM, Laitinen A, Sue-Chu M, Altraja A, Bjermer L, Laitinen LA. Evidence of airway inflammation and remodeling in ski athletes with and without bronchial hyperresponsiveness to methacholine. Am J Respir Crit Care Med. 2000;161(6):2086-91. https://doi.org/10.1164/ajrccm.161.6.9907025.

16. Moher D, Liberati A, Tetzlaff J, Altman DG, Group TP. Preferred reporting items for systematic reviews and meta-analyses: the PRISMA statement. PLoS Med. 2009;6(7):e1000097.

17. R Core Team. R: a language and environment for statistical computing. https://R-project.org. Accessec 25 Oct 2019

18. Viechtbauer W. Conducting meta-analyses in $R$ with the metafor Package. J Stat Softw. 2010. https://doi.org/10.18637/jss.v036.i03.

19. Larsson K, Ohlsen P, Larsson L, Malmberg P, Rydstrom PO, Ulriksen $\mathrm{H}$. High prevalence of asthma in cross country skiers. BMJ. 1993;307(6915):1326-9.

20. Larsson L, Hemminqsson P, Boëthius G. Self-reported obstructive airway symptoms are common in young cross-country skiers. Scand J Med Sci Sports. 1994;4(2):124-7. https://doi. org/10.1111/j.1600-0838.1994.tb00414.x.

21. Heir T, Oseid S. Self-reported asthma and exercise-induced asthma symptoms in high-level competitive cross-country skiers. Scand J Med Sci Sports. 1994;4(2):128-33. https://doi. org/10.1111/j.1600-0838.1994.tb00415.x.

22. Sue-Chu M, Larsson L, Bjermer L, SueChu M, Larsson L, Bjermer L. Prevalence of asthma in young cross-country skiers in central Scandinavia: differences between Norway and Sweden.
Respir Med. 1996;90(2):99-105. https://doi.org/10.1016/S0954 -6111(96)90206-1.

23. Michalak T, Flore P, Bouvat E, Vergés S, Samuel MJ, FavreJuvin A. Prevalence of asthma in athletes, influence of sport and environmental exposure [Prévalence de l'asthme chez l'athléte, influence de la discipline sportive et des conditions environnementales]. Sci Sports. 2002;17(6):278-85. https://doi.org/10.1016/ S0765-1597(02)00178-8.

24. Langdeau J-B, Turcotte H, Thibault G, Boulet L-P. Comparative prevalence of asthma in different groups of athletes: a survey. Can Respir J. 2004;11(6):402-6.

25. Turmel J, Poirier P, Bougault V, Blouin E, Belzile M, Boulet L-P. Cardiorespiratory screening in elite endurance sports athletes: the Quebec study. Phys Sportsmed. 2012;40(3):55-65. https:// doi.org/10.3810/psm.2012.09.1982.

26. Norqvist J, Eriksson L, Soderstrom L, Lindberg A, Stenfors N. Self-reported physician-diagnosed asthma among Swedish adolescent, adult and former elite endurance athletes. J Asthma Off J Assoc Care Asthma. 2015;52(10):1046-53. https://doi. org/10.3109/02770903.2015.1038389.

27. Eklund LM, Irewall T, Lindberg A, Stenfors N. Prevalence, age at onset, and risk factors of self-reported asthma among Swedish adolescent elite cross-country skiers. Scand J Med Sci Sports. 2018;28(1):180-6. https://doi.org/10.1111/sms.12879.

28. Sue-Chu M, Larsson L, Moen T, Rennard SI, Bjermer L. Bronchoscopy and bronchoalveolar lavage findings in crosscountry skiers with and without "ski asthma". Eur Respir J. 1999;13(3):626-32.

29. Sue-Chu M, Henriksen AH, Bjermer L. Non-invasive evaluation of lower airway inflammation in hyper-responsive elite crosscountry skiers and asthmatics. Respir Med. 1999;93(10):719-25.

30. Sue-Chu M, Karjalainen EM, Laitinen A, Larsson L, Laitinen LA, Bjermer L. Placebo-controlled study of inhaled budesonide on indices of airway inflammation in bronchoalveolar lavage fluid and bronchial biopsies in cross-country skiers. Respir Int Rev Thorac Dis. 2000;67(4):417-25. https://doi.org/10.1159/00002 9541.

31. Wilber RL, Rundell KW, Szmedra L, Jenkinson DM, Im J, Drake $\mathrm{SD}$. Incidence of exercise-induced bronchospasm in Olympic winter sport athletes. Med Sci Sports Exerc. 2000;32(4):732-7.

32. Ogston J, Butcher JD. A sport-specific protocol for diagnosing exercise-induced asthma in cross-country skiers. Clin J Sport Med Off J Can Acad Sport Med. 2002;12(5):291-5.

33. Pohjantähti H, Laitinen J, Parkkari J, et al. Exercise-induced bronchospasm among healthy elite cross country skiers and nonathletic students. Scand J Med Sci Sports. 2005;15(5):324-8. https ://doi.org/10.1111/j.1600-0838.2004.00423.x.

34. Stensrud T, Mykland KV, Gabrielsen K, Carlsen K-H. Bronchial hyperresponsiveness in skiers: field test versus methacholine provocation? Med Sci Sports Exerc. 2007;39(10):1681-6. https ://doi.org/10.1249/mss.0b013e31813738ac.

35. Sue-Chu M, Brannan JD, Anderson SD, Chew N, Bjermer L. Airway hyperresponsiveness to methacholine, adenosine 5-monophosphate, mannitol, eucapnic voluntary hyperpnoea and field exercise challenge in elite cross-country skiers. $\mathrm{Br}$ J Sports Med. 2010;44(11):827-32. https://doi.org/10.1136/ bjsm.2009.071043.

36. Dickinson J, McConnell A, Whyte G. Diagnosis of exerciseinduced bronchoconstriction: Eucapnic voluntary hyperpnoea challenges identify previously undiagnosed elite athletes with exercise-induced bronchoconstriction. Br J Sports Med. 2011;45(14):1126-31. https://doi.org/10.1136/bjsm.2010.07252 0 .

37. Żebrowska A, Głuchowska B, Jastrzębski D, KochańskaDziurowicz A, Stanjek-Cichoracka A, Pokora I. Endurance training and the risk of bronchial asthma in female cross-country 
skiers. Adv Exp Med Biol. 2015;840:29-34. https://doi. org/10.1007/5584_2014_21.

38. Kennedy MD, Davidson WJ, Wong LE, Traves SL, Leigh R, Eves ND. Airway inflammation, cough and athlete quality of life in elite female cross-country skiers: a longitudinal study: airway inflammation, symptoms, and skiing. Scand J Med Sci Sports. 2016;26(7):835-42. https://doi.org/10.1111/sms.12527.

39. Stang J, Sikkeland LIB, Tufvesson E, Holm AM, Stensrud T, Carlsen K-H. The role of airway inflammation and bronchial hyperresponsiveness in athlete's asthma. Med Sci Sports Exerc. 2018;50(4):659-66. https://doi.org/10.1249/MSS.0000000000 001478.

40. Heir T. Longitudinal variations in bronchial responsiveness in cross-country skiers and control subjects. Scand J Med Sci Sports. 1994;4(2):134-9. https://doi.org/10.1111/j.1600-0838.1994.tb004 16.x.

41. Heir T, Aanestad G, Carlsen KH, Larsen S. Respiratory tract infection and bronchial responsiveness in elite athletes and sedentary control subjects. Scand J Med Sci Sports. 1995;5(2):94-9. https://doi.org/10.1111/j.1600-0838.1995.tb00019.x.

42. Heir T, Larsen S. The influence of training intensity, airway infections and environmental conditions on seasonal variations in bronchial responsiveness in cross-country skiers. Scand J Med Sci Sports. 1995;5(3):152-9. https://doi. org/10.1111/j.1600-0838.1995.tb00029.x.

43. Sandsund M, Sue-Chu M, Helgerud J, Reinertsen RE, Bjermer L. Effect of cold exposure (-15degreeC) and salbutamol treatment on physical performance in elite nonasthmatic cross-country skiers. Eur J Appl Physiol. 1998;77:297-304. https://doi.org/10.1007/ s004210050337.

44. Sue-Chu M, Sandsund M, Helgerud J, Reinertsen RE, Bjermer L. Salmeterol and physical performance at -15 degrees $C$ in highly trained nonasthmatic cross-country skiers. Scand J Med Sci Sports. 1999;9(1):48-52.

45. Verges S, Flore P, Blanchi MPRMPR, et al. A 10-year followup study of pulmonary function in symptomatic elite crosscountry skiers-athletes and bronchial dysfunctions. Scand J Med Sci Sports. 2004;14(6):381-7. https://doi.org/10.111 1/j.1600-0838.2004.00383.x.

46. Rundell KW, Im J, Mayers LB, Wilber RL, Szmedra L, Schmitz HR. Self-reported symptoms and exercise-induced asthma in the elite athlete. Med Sci Sports Exerc. 2001;33(2):208-13.

47. Hostrup M, Kalsen A, Auchenberg M, Bangsbo J, Backer V. Effects of acute and 2-week administration of oral salbutamol on exercise performance and muscle strength in athletes: role of salbutamol on performance in athletes. Scand J Med Sci Sports. 2016;26(1):8-16. https://doi.org/10.1111/sms.12298.

48. Kalsen A, Hostrup M, Bangsbo J, Backer V. Combined inhalation of beta2-agonists improves swim ergometer sprint performance but not high-intensity swim performance. Scand J Med Sci Sports. 2014;24(5):814-22. https://doi.org/10.1111/sms.12096.

49. Wenzel SE. Asthma phenotypes: the evolution from clinical to molecular approaches. Nat Med. 2012;18(5):716-25. https://doi. org/10.1038/nm.2678.

50. Hallstrand TS, Moody MW, Wurfel MM, Schwartz LB, Henderson WR, Aitken ML. Inflammatory basis of exercise-induced bronchoconstriction. Am J Respir Crit Care Med. 2005;172(6):679-86. https://doi.org/10.1164/rccm.200412-1667OC.

51. Chang HS, Lee T-H, Jun JA, et al. Neutrophilic inflammation in asthma: mechanisms and therapeutic considerations. Expert Rev Respir Med. 2017;11(1):29-40. https://doi.org/10.1080/17476 348.2017 .1268919 .
52. Seys SF, Daenen M, Dilissen E, et al. Effects of high altitude and cold air exposure on airway inflammation in patients with asthma. Thorax. 2013;68(10):906-13. https://doi.org/10.1136/thoraxjnl2013-203280.

53. Pavord ID, Brightling CE, Woltmann G, Wardlaw AJ. Noneosinophilic cor ticosteroid unresponsive asthma. Lancet. 1999;353(9171):2213-4. https://doi.org/10.1016/S0140 -6736(99)01813-9.

54. Szefler SJ, Martin RJ, King TS, et al. Significant variability in response to inhaled corticosteroids for persistent asthma. J Allergy Clin Immunol. 2002;109(3):410-8. https://doi.org/10.1067/ mai.2002.122635.

55. Cowan DC, Taylor DR, Peterson LE, et al. Biomarker-based asthma phenotypes of corticosteroid response. J Allergy Clin Immunol. 2015;135(4):877-883.e1. https://doi.org/10.1016/j. jaci.2014.10.026.

56. Stenfors N. Self-reported symptoms and bronchial hyperresponsiveness in elite cross-country skiers. Respir Med. 2010;104(11):1760-3. https://doi.org/10.1016/j. rmed.2010.07.014.

57. Rundell KW, Anderson SD, Spiering BA, Judelson DA. Field exercise vs laboratory eucapnic voluntary hyperventilation to identify airway hyperresponsiveness in elite cold weather athletes. Chest. 2004;125(3):909-15.

58. Halvorsen T, Walsted ES, Bucca C, et al. Inducible laryngeal obstruction: an official joint European Respiratory Society and European Laryngological Society statement. Eur Respir J. 2017;50(3):1602221. https://doi.org/10.1183/13993003.02221 $-2016$.

59. Lee JW, Tay TR, Paddle P, et al. Diagnosis of concomitant inducible laryngeal obstruction and asthma. Clin Exp Allergy $\mathrm{J} \mathrm{Br}$ Soc Allergy Clin Immunol. 2018;48(12):1622-30. https://doi. org/10.1111/cea.13185.

60. 2020 Prohibited List. https://www.wada-ama.org/sites/default/ files/wada_2020_english_prohibited_list_0.pdf. Accessed 22 Mar 2020.

61. Nielsen EW, Hull JH, Backer V. High prevalence of exerciseinduced laryngeal obstruction in athletes. Med Sci Sports Exerc. 2013;45(11):2030-5. https://doi.org/10.1249/MSS.0b013e3182 98b19a.

62. Freeman MF, Tukey JW. Transformations related to the angular and the square root. Ann Math Statist. 1950;21(4):607-11. https ://doi.org/10.1214/aoms/1177729756.

63. Miller JJ. The inverse of the Freeman-Tukey double arcsine transformation. Am Stat. 1978;32(4):138-138. https://doi. org/10.1080/00031305.1978.10479283.

64. Sterne JAC, Sutton AJ, Ioannidis JPA, et al. Recommendations for examining and interpreting funnel plot asymmetry in metaanalyses of randomised controlled trials. BMJ. 2011;343:d4002d40024002. https://doi.org/10.1136/bmj.d4002.

65. Nikitina LY, Soodaeva SK, Petrovsky FI, Kotlyarova VN, Koynosov AP, Shashkova TV, Petrovskaya YA, Gasymova SS, ja Chuchalin AG. The interaction between respiratory function and exhaled nitric oxide in exercise-induced bronchoconstriction in sportsmen. Sovrem Tehnol Med. 2013;5(3):45-9.

66. Nikitina LY, Soodaeva SK, Kotlyarova VN, Petrovskaya Y, Shashkova TV, ja Gasymova SS. Efficacy of antileukotriene therapy in exercise-induced bronchospasm in skiers and biathlonists. Sovrem Tehnol Med. 2017;6(4):134-8. 